\title{
Numerical Investigation of Closed-Form Solutions for Seismic Design of A Circular Tunnel Lining (By Quasi-Static Method)
}

\author{
Alireza Rashiddel ${ }^{\mathrm{a} *}$, Mohammadreza Koopialipoor ${ }^{\mathrm{b}}$, Mir Raouf Hadei ${ }^{\mathrm{c}}$, Reza \\ Rahmannejad $^{\mathrm{d}}$ \\ ${ }^{a}$ M.Sc. Mining Engineering, Tunneling and Underground Spaces, Urmia University, Urmia, Iran. \\ ${ }^{b}$ M.Sc Student, Mining Engineering, Tunneling and Underground Spaces, Amirkabir University of Technology, Tehran, Iran. \\ ${ }^{c}$ Assistant Professor, Department of Mining Engineering, Imam Khomeini International University, Qazvin, Iran. \\ ${ }^{d}$ Professor, Department of Mining Engineering, Shahid Bahonar Kerman University, Kerman, Iran.
}

Received 10 December 2017; Accepted 31 January 2018

\begin{abstract}
In this paper, four known analytical methods including Wang (1993), Penzien (2000), Park et al. (2009), and Bobet (2010) were Evaluated based on seismic design of circular tunnel in Tehran Metro Line 6. For this purpose, a quasi-static numerical method was applied in the framework of finite difference method (FDM) under the same assumptions. In both numerical and analytical methods, to consider the nonlinear behavior of soil, linear equivalent properties of soil derived from ground analysis were incorporated in EERA software. obtained results shown that the Park's analytical solution under various conditions of interaction between the tunnel lining and soil provides very close results to the of numerical modeling. Afterward, a comprehensive validation was performed to assess the impact of the rigidity of the surrounding ground and the maximum shear strain value. In this regard, several earthquake scenarios with different shear wave rates were used to achieve a wide range of flexibility ratio $(\mathrm{F})$ and maximum shear strain. The results showed a significant difference between the results of Penzine's and Bobet's methods under the no-slip conditions and those of numerical analyses for a certain range of flexibility and shear strain ratios. In the final part of the paper, a quasi-static seismic numerical study was performed under realistic soil-structure interaction conditions to illustrate the importance of the actual interaction between the tunnel lining and surrounding soil. The results showed that the actual interaction conditions governing estimation of the axial force play a very important role. Also, it was found that Park's solution, because of the ability to consider the slip at the interface provides results very close to those of the numerical modeling. In contrast, one of the serious limitations of the other analytical methods is their inability to simulate the slip interface between the tunnel lining and soil.
\end{abstract}

Keywords: Validation; Quasi-Static Numerical Analysis; Tunnel Seismic Design; Soil-Tunnel Interaction; Shear Strain Of The Soil.

\section{Introduction}

Typically, tunnels have better performance than surface structures against earthquake. However, the different underground structures have experienced serious damage during the past earthquakes. e.g., the 1995 Kobe, Japan earthquake, the 1999 ChiChi, Taiwan earthquake, the 1999 Bolu, Turkey earthquake, the 2004 Baladeh, Iran earthquake, the 2008 Sichuan, China earthquake, and recently the 2014 Valparaisom, Chile earthquake. Therefore, seismic loading parameters have to be taken into account in the design of underground structures such as tunnels [1]. Tunnels are considered as major national projects and infrastructure investments and huge costs are spent worldwide to build these structures. However, considering the high seismic susceptibility of countries such as Iran due to their

* Corresponding author: st_a.rashiddel@urmia.ac.ir

\section{doi) http://dx.doi.org/10.28991/cej-030983}

$>$ This is an open access article under the CC-BY license (https://creativecommons.org/licenses/by/4.0/).

(C) Authors retain all copyrights. 
active tectonic, the seismic investigations for such costly structures should not be ignored. Several methods are available for the seismic design of tunnels; such as the numerical analysis of time history and quasi-static analysis, closed-form analytical method, physical modeling, and empirical methods. Considering that analytical solutions make calculations very quick and easy to obtain the axial and moment forces of the tunnel lining, they are attractive tools for initial design. In most projects, the closed-form analytical solution is used for a quick initial estimation; hence, their efficiency and integrity must be validated in all the soil environments through applying precise methods.

Wang (1993) may be the first researcher who provided a closed-form solution for internal forces of the tunnel lining structure in two states of no-slip and full-slip under seismic loading conditions. However, Wang did not provide a solution to calculate the bending moments under no-slip conditions and rather recommended applying full-slip condition solutions for no-slip conditions [2]. Penzien and Wu (1998) presented elastic closed-form solutions for axial and shear force and bending moment in the tunnel lining due to "racking deflections". Later, Penzien (2000) presented an analytical method to evaluate racking deformations in rectangular and circular tunnels to complete previously published works in this regard [3]. Hashash et al. (2001), in collaboration with a group of members of the International Tunnel Association (ITA), analyzed and designed seismic loading of tunnels with a special focus on their performance in the United States using the analytical method of Wang and Penzien [3]. Bobet (2003) also proposed a series of analytical solutions for the moment and axial force of the circular tunnel lining under seismic loading based on static loading methods of Einstein and Schwartz (1979) [4]. Hashash et al. (2005) conducted a series of two-dimensional numerical studies using finite element Plaxis software with analytical assumptions based on the differences between Wang and Penzien's analytical solution. In their study, the only no-slip state was simulated using Plaxis software. The results showed that Penzien's (2000) method considers much lower values in the estimation of the axial force under no-slip conditions [5].

Pakbaz and Yareevand (2005) conducted a two-dimensional full dynamic numerical analysis using CA2 software to estimate the impact of an earthquake on circular tunnels in an elastoplastic model and compared their obtained numerical results with those of Wang's analytical solution. They suggested that the maximum bending moment of the Wang's analytical solution in a full-slip for a flexibility ratio (F) above 20 should be multiplied by 0.6 [6]. Using finite element ADINA software, Sederat et al. (2009) performed a quasi-static analysis with the assumptions same to those of Wang but different from those of Penzien and $\mathrm{Wu}$ analytical solutions for ovalling deformation of a tunnel lining. In no-uniform assumptions, they considered different surface friction coefficients for the interface of soil and lining. The results of the quasi-static analysis with Wang's analytical solution in no-slip condition showed a difference of $2.5 \%$ in axial force and a difference of $27 \%$ in bending moments. Moreover, their results for a quasi-static analysis performed using Penzien and Wu (1998) nonlinear analytical solution showed a $5028 \%$ difference in the axial force and a $27 \%$ difference in the bending moments. These researchers highlighted the impact of interface properties on the created structural forces in the tunnel lining. Sederat et al. (2009) showed that no-slip conditions create the worst case of normal forces applied to the lining [7]. Park et al. (2009) examined the differences between seismic analytical solutions on the moment output and axial force under no-slip conditions for the ovalling deformation of the circular tunnels. Considering the relation between displacements and forces and slip effects in the soil-lining interface, Park et al. (2009) applied a shear flexibility coefficient and offered new solutions under different conditions for the ovalling deformation of the circular tunnels [8]. Bobet (2010) developed a series of analytical solutions for rectangular and circular cross-sectional underground spaces in an unlimited elastic environment subjected to free-field shear stresses under drainage and drainage conditions. The results showed that the geometry of the cavity has a small effect on structural deformation and the full-slip condition leads to less deformation. Besides, it was found that when the structure is more flexible than the ground, the drainage condition results in a reduced distortion [9]. Kouretzis et al. (2013) proposed an expression of the maximum bending moment under no slip condition in order to improve the method proposed by Wang [10].

Kontoe et al. (2014) validated four known analytical solutions under no-slip and full-slip conditions using a quasistatic method in the finite element ICFEP software under identical conditions with an analytical solution. Then, they evaluated the Park's solution in numerical methods under various sliding conditions; however, they did not apply the other solutions due to the inability to simulate slip conditions between full-slip and no-slip in this section. They concluded that the Park's solution under a variety of slip conditions is well suited to numerical methods. They also applied soil linear equivalent properties in analytical solutions as an approximate method to simulate nonlinear soil behaviours [11]. Akhlaghi and Nikkar (2014) investigated seismic behavior of circular tunnels due to propagation of shear waves in a vertical direction using the quasi-static analytical approaches and numerical methods (full dynamic) under the no-slip condition. Their results show that the axial forces determined using the analytical approaches are in an acceptable agreement with numerical analysis results, but the solutions of Penzien result in values of axial forces are not compatible with the other analytical methods and numerical analysis. On the other hand, the results show that the values of axial forces obtained by Penzien method are not reasonable. In addition, the computed bending moments show significant discrepancies [12]. Recently, Do et al (2015), examined the validity of these solutions using the FLAC3D software, with the same assumptions of Wang's analytical solution. A comparison between the numerical 
results with results of Wang's solution in no-slip condition showed a $0.83 \%$ difference in axial force and a $27 \%$ difference in bending moments. Under full-slip condition, the difference was $20.08 \%$ for the axial force and $2.55 \%$ for the bending moment. It is noteworthy that none of the above studies, consider the effect of segmental tunnel lining except the one performed by Do et al (2015) [13].

Despite the research done on the validation of analytical solutions, none of the above-mentioned works applies an exact equivalent method for the validation. Moreover, they are not appropriate for obtaining the shear strain and shear modulus using the analytical method. Ultimately, the impact of slip has not been considered on the soil-lining interface. As a result, the need for a comprehensive validation is inevitable. Among the critical limitations of analytical solutions are the inability to consider the real interaction between the tunnel lining and soil (except the Park's solution), modeling only circular cross-section tunnels, failure to consider nonlinear behavioral models for soil, and inefficiency for a saturated environment (except the Bobet's solution).

In the first part of this research, Tehran Metro Line 6 as an underground structure built on a soft urban environment was subjected to seismic analyses using the seismic analytical methods. Next, using FDM code under no-slip and fullslip interaction conditions, the model was simulated with the same assumptions of the analytical solutions and the obtained results were compared. Next, to carry out a comprehensive validation, the effect of soil rigidity and maximum shear strain of free field was considered in a wide range of Young's modulus and a maximum shear strain in order to analyze the difference between analytical and numerical solutions. Eventually, to determine the significance of the actual conditions of interaction between the soil and the lining, in the numerical method of the interface element was used with realistic interaction conditions and compared with the interaction conditions of no-slip and full-slip analytical solutions and the actual conditions of Park's solution. One of the indirect goals of this paper is to achieve a quasi-static numerical model for the seismic design of tunnels such that it lacks the limitations of analytical methods.

\section{Case Study}

Tehran Metro Line 6 is one of the most important and longest lines of Tehran Metro that links the southeast of the city of Tehran to its northwest. In its original design, the length of the line was over $30 \mathrm{~km}$ and included 27 stations (Figure 1) [14]. Recently, with the development of the southern part of Line 6, the length and the number of stations of this line have been extended to $38 \mathrm{~km} 31$ stations, respectively. Currently, Tehran Metro Line 6 is the longest subway line in the Middle East.

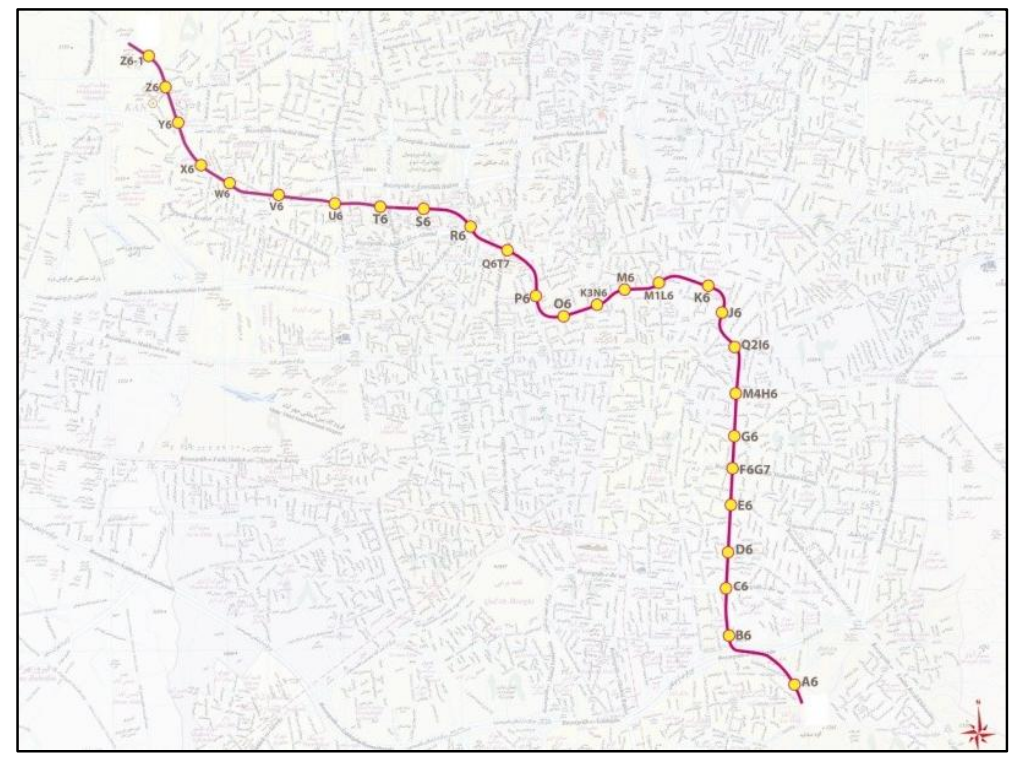

Figure 1. The main route of Tehran Metro Line 6

\subsection{Classification of Earth-type based on Seismic view}

Using the standard penetration test (SPT) numbers at the end of the BH-SL612 borehole and analyzing these numbers based on the correlation relations by various references, the average shear wave velocity for the range of the tunnel depth was estimated to be about $490 \mathrm{~m} / \mathrm{s}$ (Figure 2) [15].

According to the risk analysis of the Metro Line 6, Tehran is located in an area with a high earthquake occurrence probability and maximum ground acceleration equal to $4.8 \mathrm{~m} / \mathrm{s}^{2}$, every 50 years (Figure 3 ). In this calculation, the acceleration of the maximum ground level was considered to be $5.6 \mathrm{~m} / \mathrm{s}^{2}$, suggesting an earthquake of magnitude 8 in a distance of $10 \mathrm{~km}$ from the earthquake center [16]. In Tables 1 and 2, the values of the required seismic parameters for the seismicity of the tunnel for the BH-SL612 borehole are presented. 


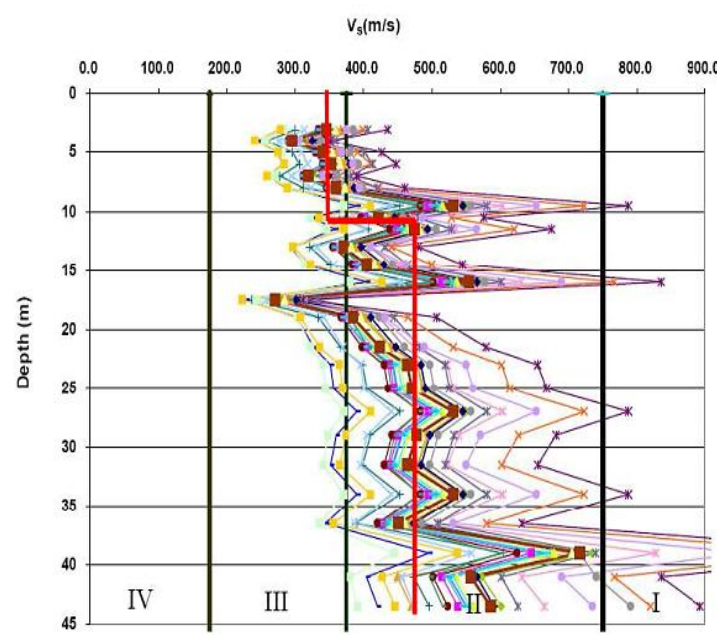

Figure 2. Shear wave velocity values versus depth [15]

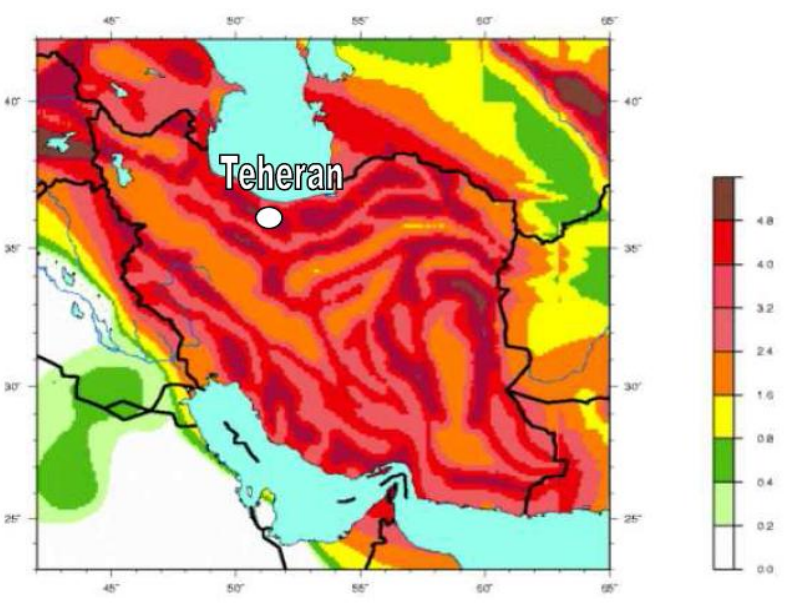

Figure 3. Peak ground acceleration with $10 \%$ probability of exceedance in 50 years [16]

Table 1. Earthquake risk analysis parameters of Tehran Metro Line 6 [16]

\begin{tabular}{cc}
\hline Parameter value & Parameter \\
\hline 8 & moment magnitude \\
$0.56 \mathrm{~g}$ & Peak particle acceleration associated with surface of earth \\
10 & Seismic fault distance $(\mathrm{km})$ \\
\hline
\end{tabular}

Table 2. Dynamic Properties of Borehole BH-SL612 [15]

\begin{tabular}{|c|c|}
\hline Parameter & Parameter value \\
\hline Peak particle acceleration associated with depth tunnel $\left(\mathrm{m} / \mathrm{s}^{2}\right)$ & $a_{s}=5.6 \times 0.7=3.92$ \\
\hline $\begin{array}{l}\text { Apparent velocity of S-wave propagation at the depth of the } \\
\text { tunnel for borehole BH-SL612 (m/s) }\end{array}$ & $C_{S}=490$ \\
\hline Peak particle velocity associated with $S$-waves $(\mathrm{m} / \mathrm{s})$ & $V_{s}=a_{s} \frac{140+180}{2}=0.64$ \\
\hline $\begin{array}{l}\text { Maximum free-field shear strain of soil obtained by analytical } \\
\text { method }\end{array}$ & $\gamma_{\max }=\frac{V_{s}}{C_{s}}=0.0013$ \\
\hline Soil height on bedrock $(\mathrm{m})$ & $h=60$ \\
\hline Dry density $\left(\mathrm{Mg} / \mathrm{m}^{3}\right)$ & $\rho_{d r y}=1.7$ \\
\hline $\begin{array}{l}\text { The strain-compatible shear moduli of the soil strata computed } \\
\text { from EERA (Mpa) }\end{array}$ & $G_{d y n}=380.5$ \\
\hline Dynamic Poisson ratio for cohesive soil [17] & $v_{d y n}=0.48$ \\
\hline Dynamic elastic modulus (Mpa) & $E_{d y n}=2 G_{d y n}\left(1+v_{d y n}\right)=1126.2$ \\
\hline Dynamic bulk modulus (Mpa) & $K_{d y n}=\frac{E_{d y n}}{3\left(1-2 v_{d y n}\right)}=9385$ \\
\hline
\end{tabular}

In general, one of the factors that affect seismic design results of underground structures is the maximum free-field shear strain applied in the analytical and quasi-static numerical methods. To calculate this parameter, we can use the simple analytic relationships in Table 2. Also, we can apply numerical methods such as EERA, as open source software, regardless of the interaction between the ground and the structure. In this regard, the maximum shear strain value depends on the type of acceleration record and soil characteristics. Moreover, the use of maximum acceleration values instead of applying acceleration in the bedrock and converting it to acceleration at the depth of the burial tunnel is not accurate enough. Since the closed-form and the quasi-static relationship of the maximum shear strain parameter are used instead of the maximum acceleration, to achieve a higher accuracy, the created maximum shear strain in a soil profile should be calculated by applying an earthquake as an acceleration record. This approach is also pointed out by researchers such as Park \& Partner (2006) and Bazz \& Besharat (2008) [19-20]. 
To use the numerical method, a linear one-dimensional linear equation analysis was used in the EERA software of the University of Southern California. The acceleration record data used in this study are presented in Table 3 . These data are the result of the risk analysis of the Tehran Metro Line 6 site. According to the site conditions and the acceleration record, the maximum applied shear strain is calculated according to Figure 4. by the EERA software, which provides a much smaller value than the one obtained from the analytical method in Tables 2 to 4 . shows the parameters of the tunnel lining and Figure 5. shows the structure of tunnel lining.

Table 3. Acceleration record parameters used in EERA software

\begin{tabular}{cc}
\hline ChiChi, Taiwan CHY006 & Parameters value \\
\hline 7.62 & Earthquake Magnitude $(\mathrm{Mw})$ \\
0.56 & $\mathrm{PGA}(\mathrm{g})$ \\
0.66 & $\mathrm{PAV}(\mathrm{m} / \mathrm{s})$ \\
9.76 & Source-to-Site Distance $(\mathrm{Km})$ \\
150 & Duration (Sec) \\
1999 & Year \\
1.57 & Scaling Factor \\
\hline
\end{tabular}

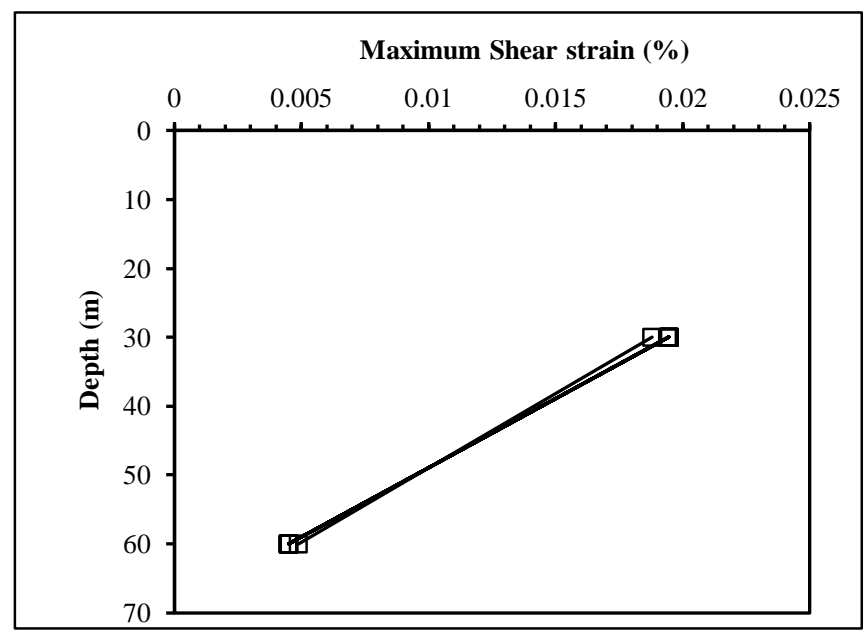

Figure 4. Results maximum shear strain of 1D linear equivalent response analyses in terms of vertical profiles

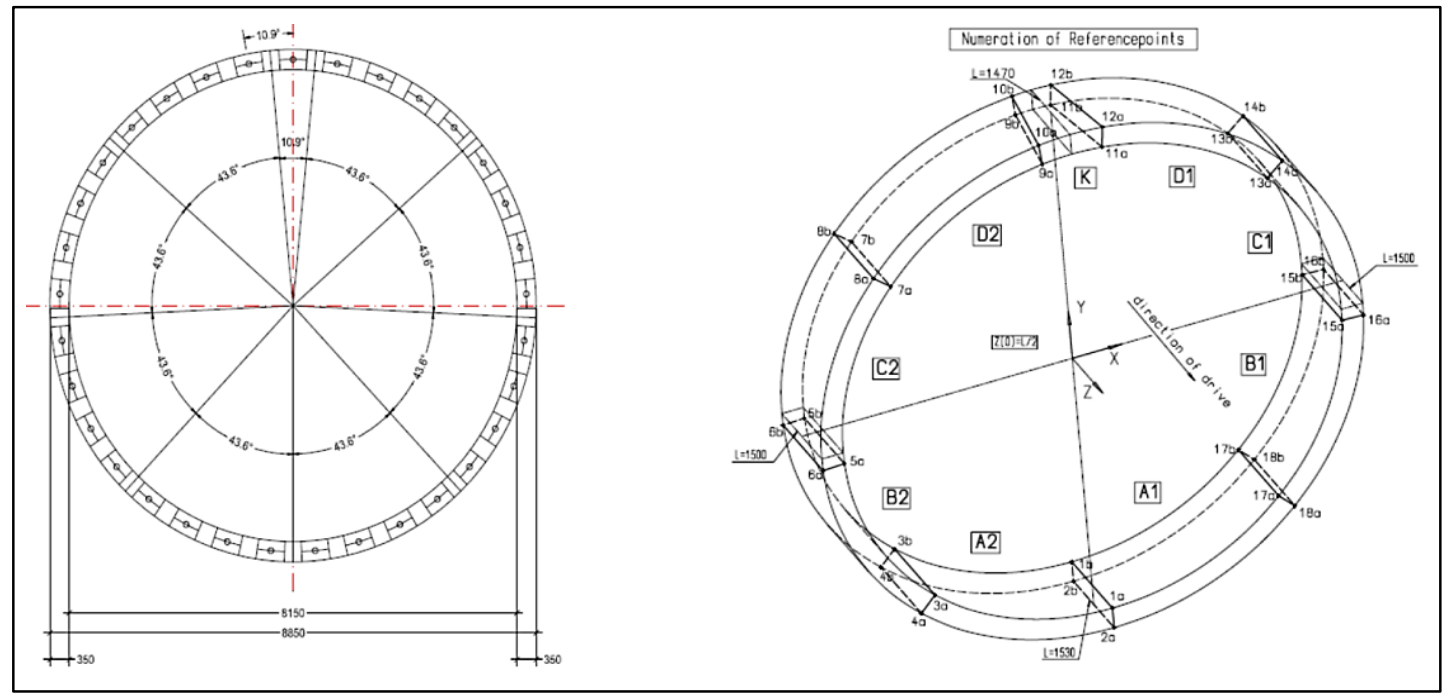

Figure 5. Geometry and arrangement of the segments in a ring [16]

Table 4. Tunnel lining Parameters of Tehran Metro Line 6 [16]

\begin{tabular}{ccccc}
\hline $\begin{array}{c}\text { radius of the tunnel } \\
(\mathbf{m})\end{array}$ & $\begin{array}{c}\text { Poisson ratio of } \\
\text { Tunnel lining }\end{array}$ & $\begin{array}{c}\text { Thickness of the } \\
\text { tunnel lining (m) }\end{array}$ & $\begin{array}{c}\text { Modulus of elasticity } \\
\text { of tunnel lining (MPa) }\end{array}$ & $\begin{array}{c}\text { The inertia moment of the } \\
\text { Continuous tunnel lining (M/M) }\end{array}$ \\
\hline 4.425 & 0.2 & 0.35 & $27.8 \times 103$ \\
\hline
\end{tabular}




\section{Methodology}

When the seismic compression and shear waves propagate through the earth mass, they deform any structure inside and on the surface of the earth depending on the flexibility $(\mathrm{F})$ and compressibility $(\mathrm{C})$ of these structures and the maximum shear strain of the earth. The tunnel response to the vibrational motion of the earthquake may be represented by three major deformations: axial, curvature, ovalling/ racking deformation (Wang, 1993). As shown in Figure 6, when the shear waves propagate perpendicular to the tunnel axis, they form ovalling or racking deformations depending on the cross-sectional shape of the tunnel lining [3]. Ovalling or racking deformations caused by the vertical propagation of the shear seismic waves are the components with the maximum effect on the behavior of the tunnel lining under seismic loading (except for the tunnel cut by a fault) [5].

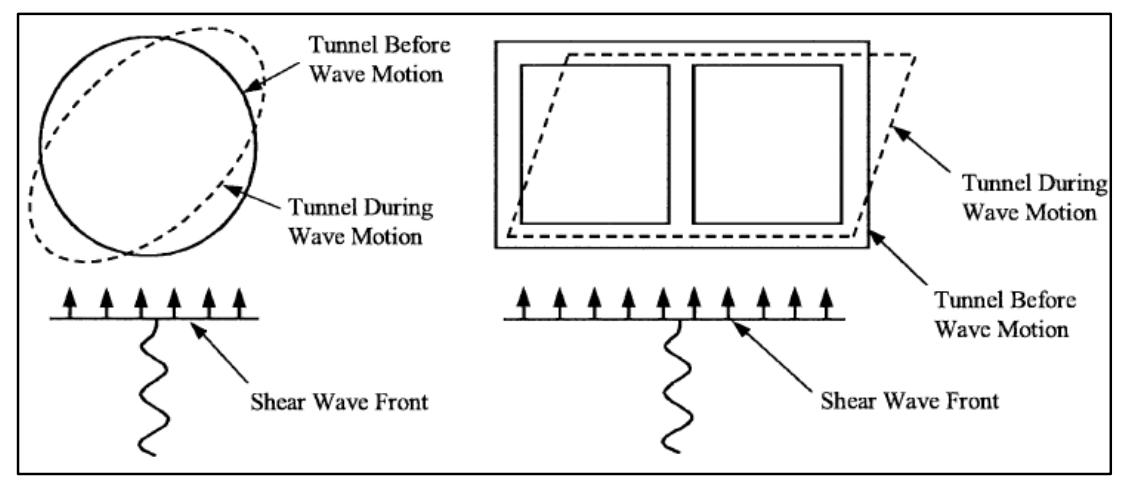

Figure 6. Deformation modes of tunnels due to seismic waves [3]

The forces and moments induced in the tunnel structure caused by seismic waves are divided into two main groups: the first group is due to the propagation of waves in the tunnel axis and the second one is due to the propagation of waves perpendicular to the axis of the tunnel (Figure 7) [3]. Considering that the propagation of shear waves perpendicular to the tunnel axis create the most critical condition for internal structural forces and the tunnel lining deformations (Wang 1993), we applied analytical methods for the tunnel response into ovalling of the tunnel axis.

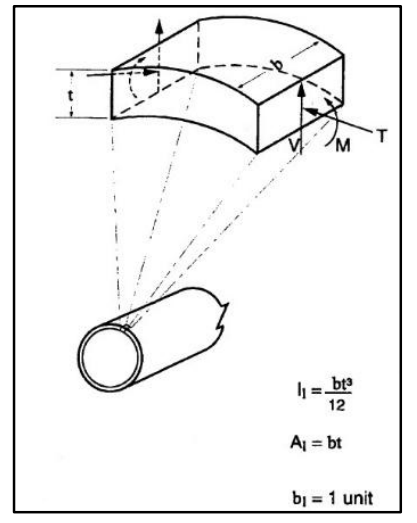

Induced circumferential forces and moments caused by waves propagating perpendicular to tunnel axis

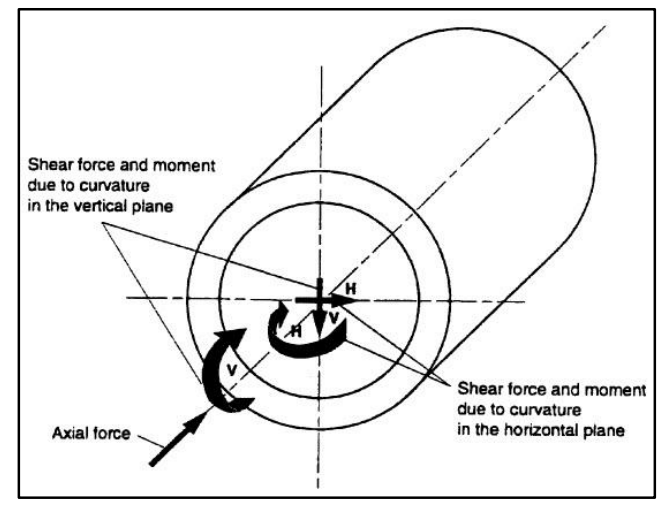

Induced forces and moments caused by waves propagating along tunnel axis

Figure 7. Induced forces and moments caused by seismic waves [3]

In analytical methods, two methods are commonly applied to estimate the induced forces due to ovalling in the tunnel axis. One of these methods is simpler and approximate while the other is more accurate and more numerical. In the first method, which is referred as the method of changing the shape of the free-field, the ground strain caused by seismic waves is determined in the absence of the structure and the interaction of the structure and soil is not taken into account. Therefore, this method, depending on the rigidity of the structure relative to the ground, may estimate the structural deformations upwardly or downwardly [3]. In the second method, called the interaction method, the interaction between the soil and the structure is considered.

In this research, four analytical solutions (e.g., Wang (1993), Penzien (2000), Park et al. (2009), and Babet (2010)) were validated using the ovalling interaction for the circular tunnels under no-slip and full-slip conditions. For this purpose, the quasi-static method in the FDM code with the assumptions same as those of the analytical solution was employed. The quasi-static analysis can also be performed in the form of a force, in which seismically induced inertia forces are introduced as a constant body force, or the deformation method, in which the mesh is subjected to shear deformation, as schematically illustrated in Figure 8 [11]. 


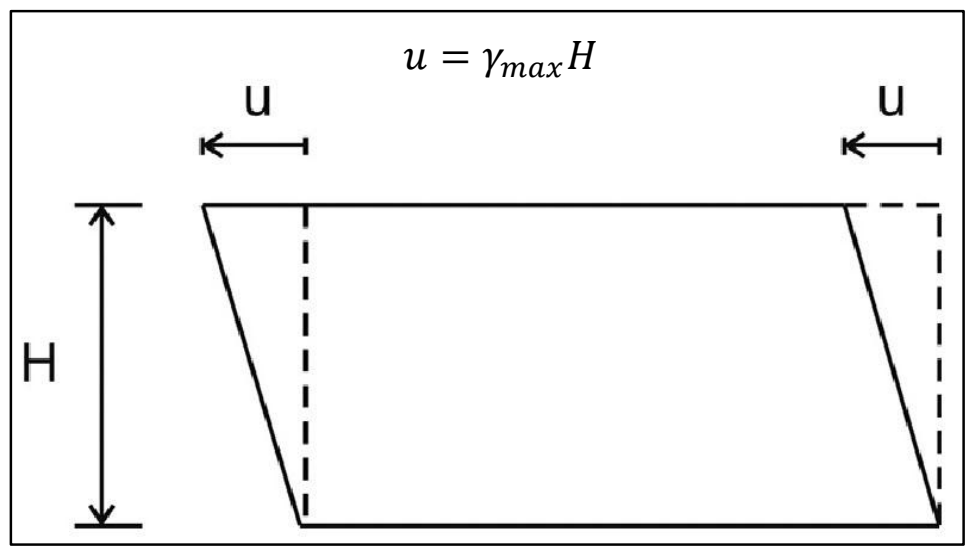

Figure 8. Schematic representation of the mesh configuration in a quasi-static deformation based analysis consistent with simple-shear conditions [11]

\subsection{Closed form Analytical Methods}

\subsubsection{Free-field Deformation Method}

The simplest way to estimate the ovalling deformation is to assume that the deformations in the circular tunnels correspond to those of the free-field, thereby the interaction between the lining and the soil is ignored or, in other words, the tunnel is considered without a support system. In this method, assuming the circular excavation, the amount of diametric strain of the earth during an earthquake without the assumption of the tunnel excavation depends only on the maximum value of the free-field shear strain $\left(\gamma_{\max }\right)$ of the earth, the value of which is determined from Eq. (1). This value is increased by assuming perforated and if the section of excavation is circular, it causes distortion and its value is calculated from Eq. (2) [5]. (It has to be noted that assuming an excavation, the diametric strain would be about two to three times without excavation [2]).

$$
\begin{aligned}
& \frac{\Delta d_{\text {free }} \text {-field }}{d}= \pm \frac{\gamma_{\text {max }}}{2} \\
& \frac{\Delta d_{\text {free }- \text { field }}}{d}= \pm 2 \gamma_{\max }\left(1-v_{m}\right)
\end{aligned}
$$

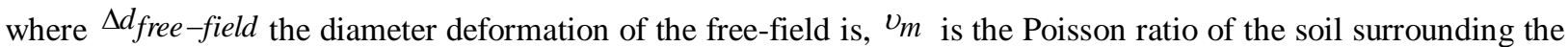
tunnel, and $\mathrm{d}$ is the diameter of the tunnel.

If the tunnel stiffness is very small compared to that of the surrounding soil, the assumption of the cavity existence in calculating of the shear deformation is closer to reality. If the tunnel stiffness is equal to the soil stiffness, the assumption of the non-perforated in calculating the shear deformation will be closer to reality. When the tunnel rigidity is considerable compared to that of the surrounding area, the shear deformation values will also be less than that of the tunnel without a support system. Because in most tunnels, the rigidity of the lining is noticeable in relation to its peripheral, the interaction between the lining and the soil should be considered. Also, the forces and moments generated by the propagation of waves perpendicular to the tunnel axis are strongly influenced by the ratio of tunnel stiffness to the surrounding area. As a result, an interaction method is appropriate to determine the forces. In other words, the free-field deformation method is suitable for a tunnel structure that is flexible in its environment, like all tunnels excavated in rocks and soils. In this case, it is reasonable to assume that the tunnel deformation follows its environment. However, this assumption is not true for rigid structures in soft soils because the calculated deformations of the ground under these conditions may be much larger due to the soft nature of soils, which are considered to be rigid structures. When the calculated strain for the earth exceeds the permitted strain of the tunnel lining material, engineers rarely implement the design [21]. In general, this simple method provides an estimation of the high level of the created strains by structures due to the transmission of waves. The greatest advantage of this method is the need for a minimum number of input data.

\subsubsection{Interaction Method}

When the tunnel structure is more rigid than the surrounding soil, the tunnel structure resists against it, rather than being adjusted with the deformations induced by the ground. Hence, in this method, taking into account the difficulty of the alternative structure with the Earth's removed mass from the media, it is possible to obtain a good approximation of the interaction of the structure-media and the applied distortion to the structure during a seismic event. The analysis of the tunnel-ground interaction, which considers both the tunnel rigidity and the earth, plays a key role in the seismic 
response of the tunnel [21].

\subsubsection{Wang's Analytical Solution}

The first interactive analytical method investigated in the present work is Wang's solution (1993). In this method, the tunnel rigidity relative to the surrounding soil is based on the compression and flexibility $(\mathrm{C}, \mathrm{F})$ ratios provided by Peck et al (1972) in accordance with Equations 3 and 4, which provide a measure of tensile rigidity and bending rigidity of the environment relative to the lining, respectively [3-11].

$$
\begin{aligned}
& C=\frac{E_{m}\left(1-v_{l}^{2}\right) \mathrm{r}}{E_{l} t\left(1+v_{m}\right)\left(1-2 v_{m}\right)} \\
& F=\frac{E_{m}\left(1-v_{l}^{2}\right) \mathrm{r}^{3}}{6 E_{l} I\left(1+v_{m}\right)}
\end{aligned}
$$

Where $E_{m}$ is the Young modulus of ground around the tunnel.

According to Peck et al. (1972), if the flexibility ratio (F) is less than 20, the tunnel lining is rigid and the interaction between the lining and the soil should be taken into account [21]. The axial force and maximum bending moment in the tunnel structure, in addition to the function of compression and flexure ratios, are also a function of the tunnel slip conditions relative to the surrounding environment. Assuming a full-slip without vertical separation, the maximum internal forces are calculated from the following relationships [3].

$$
\begin{aligned}
& T_{\text {max }}= \pm \frac{1}{6} K_{1} \frac{E_{m}}{\left(1+v_{m}\right)} r \gamma_{\text {max }} \\
& M_{\text {max }}= \pm \frac{1}{6} K_{1} \frac{E_{m}}{\left(1+v_{m}\right)} r^{2} \gamma_{\text {max }} \\
& K_{1}=\frac{12\left(1-v_{m}\right)}{2 F+5-6 v_{m}}
\end{aligned}
$$

Where $K_{1}$ is the coefficient of the lining response under full-slip conditions in Wang's solution.

According to several studies, the slip at the interface of the tunnel lining and surrounding soil is only possible for the excavated tunnels in soft soils, where the severe seismic loading is intense. For most tunnels, the interface condition of the tunnel lining and the surrounding soil is between the full-slip and no-slip mode; thus, both modes should be considered to obtain critical internal forces for the lining and deformation. However, full-slip mode assumptions under simple shear can significantly estimate the maximum axial forces less. Therefore, it is recommended assuming the total no-slip mode between the tunnel lining and the surrounding soil in the axial response in accordance with Equation 8 [3].

$$
\begin{aligned}
& T_{\max }= \pm K_{2} \tau_{\max } r=_{-}^{+} K_{2} \frac{E_{m}}{2\left(1+v_{m}\right)} r \gamma_{\max } \\
& K_{2}=1+\frac{F\left[\left(1-2 v_{m}\right)-\left(1-2 v_{m}\right) C\right]-\frac{1}{2}\left(1-2 v_{m}\right)^{2}+2}{F\left[\left(3-2 v_{m}\right)+\left(1-2 v_{m}\right) C\right]+C\left[\frac{5}{2}-8 v_{m}+6 v_{m}{ }^{2}\right]+6-8 v_{m}}
\end{aligned}
$$

Where $K_{2}$ the coefficient of the lining response under no-slip is conditions in the Wang's solution and $\tau_{\max }$ is the maximum free-field shear stress.

\subsubsection{Analytical Solution of Penzien}

Penzien and $\mathrm{Wu}$ (1998) proposed elastic closed-form solutions for axial force, shear force, and bending moment in the tunnel lining due to ovalling deflection. Penzien (2000) presented an analytical method for evaluating the racking/ovalling of rectangular and circular tunnels, which completed the previous work. To evaluate the angular strain of the structure, a distortion ratio of the lining-soil was defined as Equation 10 [3]:

$$
R=\frac{\Delta_{\text {structure }}}{\Delta_{\text {free-field }}}
$$

Where $\Delta_{\text {structure }}$ is racking deflection of rectangular tunnel cross-section and $R$ is lining-soil racking ratio. Assuming a full- slip condition, the response to the axial force, bending moment, and shear force is explained by the interaction of the soil-structure during the earthquake occurring in the tunnel lining [3]:

$\pm \Delta d_{\text {lining }}^{n}= \pm R^{n} \Delta d_{\text {free-field }}$ 


$$
\begin{aligned}
& T(\theta)=-\frac{12 E_{l} I \Delta d_{\text {lining }}^{n}}{d^{3}\left(1-v_{l}^{2}\right)} \cos 2\left(\theta+\frac{\pi}{4}\right) \\
& M(\theta)=-\frac{6 E_{l} I \Delta d_{\text {lining }}^{n}}{d^{2}\left(1-v_{l}^{2}\right)} \cos 2\left(\theta+\frac{\pi}{4}\right) \\
& V(\theta)=-\frac{24 E_{l} I \Delta d_{\text {lining }}^{n}}{d^{3}\left(1-v_{l}^{2}\right)} \sin 2\left(\theta+\frac{\pi}{4}\right) \\
& R^{n}= \pm \frac{4\left(1-v_{m}\right)}{\left(\alpha^{n}+1\right)} \\
& \alpha^{n}=\frac{12 E_{l} I\left(5-6 v_{m}\right)}{d^{3} G_{m}\left(1-v_{l}^{2}\right)}
\end{aligned}
$$

Where $\Delta d_{\text {lining }}^{n}$ and $R^{n}$ are diametric deflection of the lining in non-perforated and the lining-soil racking ratio of the circular tunnel soil under normal loading, respectively; $\theta$ is angular position of the tunnel lining, $\alpha^{n}$ is the coefficient applied to calculate the lining-soil racking ratio of the tunnel circular only under normal loading, and $G_{m}$ is the shear modulus of the earth around the tunnel.

Under no-slip conditions, Penzien's relations (2000) are expressed as follows [3]:

$$
\begin{aligned}
& \pm \Delta d_{\text {lining }}= \pm R \Delta d_{\text {free }- \text { field }} \\
& T(\theta)=-\frac{24 E_{l} I \Delta d_{\text {lining }}}{d^{3}\left(1-v_{l}^{2}\right)} \cos 2\left(\theta+\frac{\pi}{4}\right) \\
& M(\theta)=-\frac{6 E_{l} I \Delta d_{\text {lining }}}{d^{2}\left(1-v_{l}^{2}\right)} \cos 2\left(\theta+\frac{\pi}{4}\right) \\
& V(\theta)=-\frac{24 E_{l} I \Delta d_{\text {lining }}}{d^{3}\left(1-v_{l}^{2}\right)} \sin 2\left(\theta+\frac{\pi}{4}\right) \\
& R= \pm \frac{4\left(1-v_{m}\right)}{(\alpha+1)} \\
& \alpha=\frac{24 E_{l} I\left(3-4 v_{m}\right)}{d^{3} G_{m}\left(1-v_{l}^{2}\right)}
\end{aligned}
$$

Where $\Delta d_{\text {lining }}$ is the diametric deflection in non-perforated and $\alpha$ is the used coefficient to calculate the lining-soil racking ratio of the circular tunnel.

\subsubsection{Analytical solution of Park}

In the following, the presented relationships in the analytical solution of Park et al. (2009) are discussed for circular tunnels subjected to ovalling deformation induced by the shear waves perpendicular to the tunnel axis. In full-slip conditions, Equations 23 and 24, and in no-slip conditions, Equations 25 to 27 are expressed as follows [8]:

$$
\begin{aligned}
& \frac{T_{P T T O}(\mathrm{~F}-\mathrm{S})}{G_{S} \gamma_{C} R}=-\frac{4\left(1-v_{S}\right)}{\left(2 \mathrm{~F}+5-6 v_{S}\right)} \cos 2\left(\theta+\frac{\pi}{4}\right) \\
& \frac{M_{P T T O}(\mathrm{~F}-\mathrm{S})}{G_{S} \gamma_{C} R^{2}}=-\frac{4\left(1-v_{S}\right)}{\left(2 \mathrm{~F}+5-6 v_{S}\right)} \cos 2\left(\theta+\frac{\pi}{4}\right) \\
& \frac{T_{P T T O}(N-\mathrm{S})}{G_{S} \gamma_{C} R}=-\frac{4\left(1-v_{S}\right)}{\Delta^{\prime}}\left\{F+\left(\frac{1}{2}-v_{S}\right) \mathrm{C}+2\right\} \cos 2\left(\theta+\frac{\pi}{4}\right) \\
& \frac{M_{P T T O}(N-\mathrm{S})}{G_{S} \gamma_{C} R^{2}}=-\frac{4\left(1-v_{S}\right)}{\Delta^{\prime}}\left\{1+\left(\frac{1}{2}-v_{S}\right) \mathrm{C}\right\} \cos 2\left(\theta+\frac{\pi}{4}\right) \\
& \Delta^{\prime}=F\left[\left(3-2 v_{S}\right)+\left(1-2 v_{S}\right) \mathrm{C}\right]+\mathrm{C}\left[\frac{5}{2}-8 v_{S}+6 v_{S}^{2}\right]+6-8 v_{S}
\end{aligned}
$$

Where $G_{s}$ is the shear modulus of the soil around the tunnel, $\gamma_{c}$ is the mean free-field shear strain at high depth $2 R$, $\Delta^{\prime}$ is the coefficient of coverage response in no-slip conditions in the Park's solution, and the $v_{s}$ is the Poisson coefficient of soil around the tunnel.

\subsubsection{Bobet's Analytical Solution}

The presented relationships in the closed form Bobet's (2010) analytical solution were applied for a circular tunnel 
under with ovalling deformation due to the impact of shear waves perpendicular to the tunnel axis. In full-slip and drainage conditions, Equations 28 and 29, and in the no-slip and drainage conditions Equations 31 to 32 are as follows [9]:

$$
\begin{aligned}
& T=-\frac{12\left(1-v_{m}\right)}{3\left(5-6 v_{m}\right)+\left(1-v_{m}\right) \mathrm{F}^{\prime}} G_{m} \gamma_{\max } r \sin 2 \theta \\
& M=T . r \\
& \mathrm{~F}^{\prime}=E_{m} r^{3}\left(1-v_{l}^{2}\right) / E_{l} I_{l}\left(1-v_{m}^{2}\right) \\
& T=-\left(1-\mathrm{C}_{2}\right) \mathrm{G}_{m} \gamma_{\max } r \sin 2 \theta \\
& M=-\frac{1}{2}\left(1+\mathrm{C}_{1}+\mathrm{C}_{2}\right) \mathrm{G}_{m} \gamma_{\max } r^{2} \sin 2 \theta \\
& \mathrm{C}_{1}=-2 \frac{\left(1-v_{m}\right)^{2} C^{\prime}+\left(1-v_{m}\right)-\left[\left(1-v_{m}\right) C^{\prime}+4\right] 3 / \mathrm{F}^{\prime}}{\left(1-v_{m}^{2}\right) C^{\prime}+\left(1-v_{m}\right)\left(3-2 v_{m}\right)+\left[\left(1-v_{m}\right)\left(5-6 v_{m}\right) C^{\prime}+4\left(3-4 v_{m}\right)\right] 3 / \mathrm{F}^{\prime}} \\
& \mathrm{C}_{2}=\frac{1}{3} \frac{\left(1-v_{m}\right) C^{\prime}-2-\mathrm{C}_{1}\left[\left(1-v_{m}\right) C^{\prime}+4 v_{m}\right]}{\left(1-v_{m}\right) C^{\prime}+2} \\
& \mathrm{C}^{\prime}=\frac{E_{m}}{r\left(1-v_{l}^{2}\right) /} E_{l} \mathrm{~A}\left(1-v_{m}^{2}\right)
\end{aligned}
$$

Where $F^{\prime}, C^{\prime}, C_{1}$ and $C_{2}$ are the coefficients applied in the analytic relations.

\subsection{Numerical Method}

The numerical method applied in the present work is a two-dimensional explicit finite difference program for engineering mechanics computation. This program simulates the behavior of structures built of soil, rock and other materials that may undergo plastic flow when their yield limits are reached. Materials are represented by elements, or zones, which form a grid that is adjusted by the user to fit the shape of the object to be modeled. Each element behaves according to a prescribed linear or nonlinear stress/strain law in response to the applied forces or boundary restraints. The material can yield and flow and the grid can deform (in large-strain mode) and move with the material that is represented.

In order to investigate the results obtained from the analytical methods of seismic design of the tunnel lining, a numerical verification based on the finite difference code was used. Since the results obtained from the analytical methods for soft soils are very conservative, a pure seismic numerical modeling (without considering static loads) was performed to ensure the accuracy of the results of the closed form solutions. The assumptions employed in the numerical method for equating the analytical and numerical analysis are as follows $[5,7,11,22]$ :

- Plane strain condition is considered.

- A numerical model is created in a layer of soil.

- The tunnel and lining are circular and integrated, respectively.

- The soil and lining of the tunnel are linear elastic and non-mass.

- The interface of the tunnel lining and the peripheral soil is in full-slip and no-slip conditions.

- Excavation is performed simultaneously with the installation of the tunnel-lining element (regardless of the effect of the manufacturing sequence).

- Seismic loading is applied as a shear loading to the end of the upper boundary that simulates the conditions of the pure shear. This loading creates a reverse triangular deformation along the side boundaries of the model and their displacement uniformly along the upper boundary (Figure 9-b).

- Shear loading is applied to create a shear strain under completely drained conditions. 
In this research, a quasi-static analysis was adopted based on the deformation method, because this method is consistent with the analytical solution assumptions and does not suffer from the inherent constraints associated with the force method; e.g., the sensitivity to the dimensions of the model [11]. In all previous studies, except for the research of Kontoe et al. (2014), the force method has is used and the initial stress conditions are established in the model. Finally, the internal forces of the tunnel lining are derived from the difference in the internal forces in the quasi-static phase of the static phase, which cannot be a proper procedure due to the inherent constraints of this method and its inconsistency with the assumptions of analytical solutions. The mesh grid of the numerical model has a soil layer on a bedrock with a thickness of $\mathrm{H}=60 \mathrm{~m}$. The mesh partitions are designed such that the grid around the tunnel is radial and small. Moreover, a simple type of mesh was used to close artificial boundaries (Figure 9-a). The side boundaries of the mesh network are $40 \mathrm{~m}$ from the center of the tunnel. The data from Table 2 . and Table 4 . were used for the properties of the soil materials and the tunnel lining. In the modelling process, first, the geometry of the model was created in a layer and in a linear and elastic environment without gravitational acceleration of the earth with the solid element. In order to restrict the boundaries, the bottom boundary was restricted in both the vertical and horizontal directions while the top and side boundaries were restricted only in the vertical direction. Then, the tunnelling and installation of the tunnel lining element were performed simultaneously [11-22]. In numerical models, the tunnel cover has been shown with 136 structural elements rigidly connected to each other. The number of the elements is governed by the size of the surrounding zones. Therefore, to increase the accuracy, one structural element is created in each surrounding zone of the excavated tunnel. For modelling the interaction modes, a full-slip and no-slip interface between the tunnel lining and the soil around the tunnel were performed as follow [7, 11, 23]:

A) In the direction normal to the lining, the soil and the lining are completely connected b) In the tangential directions; there is a full-slip and no-slip on the tunnel lining. In the no-slip mode, it is assumed that there is complete bonding or adhesion between the lining and the soil to the tangent. As a result, the attache element is used in the numerical method to connect the lining and soil. However, in the case of full-slip, no tangential resistance is considered or frictional resistance between the soil and the lining; thus, the parameters related to tangential resistance are considered zero. To model the full-slip mode, an interface element with a very high normal rigidity coefficient was used according to the reference [11] and other parameters according to Table 5.

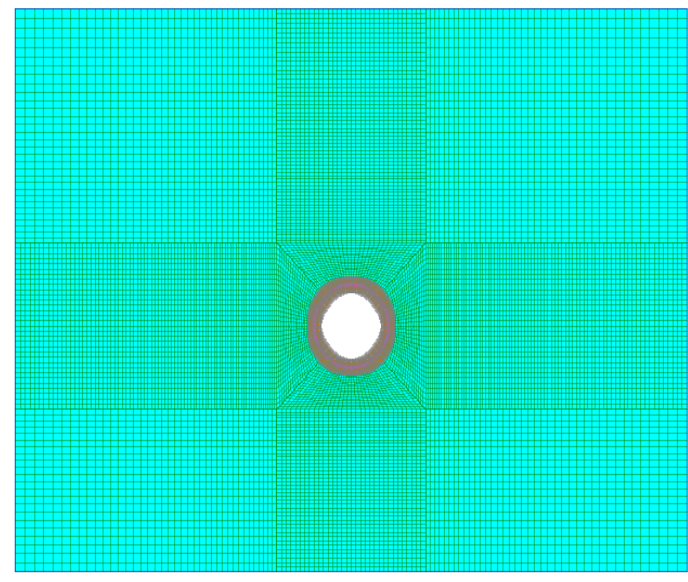

a) Finite Difference mesh used in the FDM

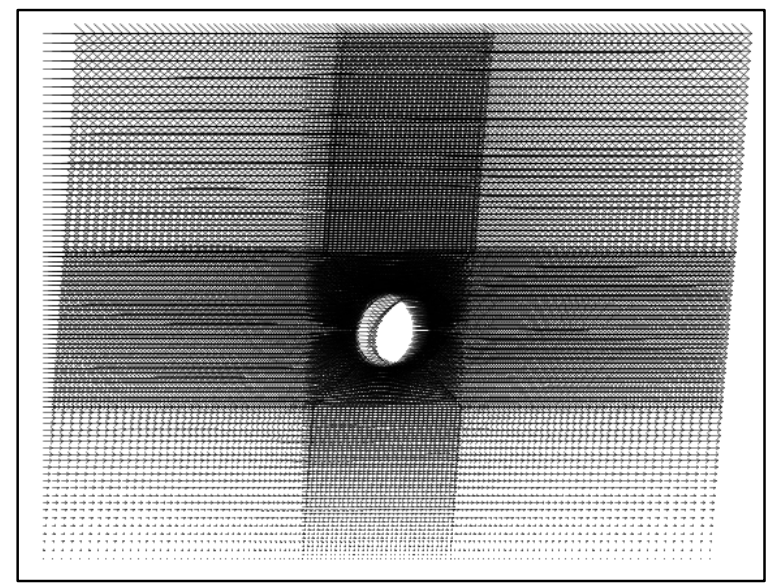

b ) Deformation of numerical model by seismic loading

Figure 9. The geometry of numerical model before and after seismic loading

Table 5. The values of the interface element parameters between the tunnel lining and soil in full-slip condition

\begin{tabular}{cc}
\hline Parameter value & Parameter \\
\hline Normal stiffness coefficient between lining and soil $(\mathrm{Pa} / \mathrm{m})$ & $1 \times 10^{10}$ \\
Shear stiffness coefficient between lining and soil $(\mathrm{Pa} / \mathrm{m})$ & 1000 \\
Cohesion between lining and soil $(\mathrm{Pa})$ & 0.0 \\
Angle of dilation between lining and soil & 0.0 \\
Angle of friction between the lining and soil & 0.0 \\
Tensile bond strength between the lining and soil $(\mathrm{Pa})$ & $1 \times 10^{5}$ \\
Shear strength ratio to tensile strength between lining and soil & 100 \\
Slip conditions between the lining and soil & on
\end{tabular}

Ultimately, a relation is made between the displacement magnitude of the upper boundary of the model with the maximum free-field shear strain $\left(\gamma_{\max }\right)$ and the height of the model $(\mathrm{H})$. As a result, the obtained maximum displacement value at the upper boundary $(u)$ is achieved from Equation 36 [11-23]. At the last step, the horizontal load is applied to the surface, which produces the maximum displacement of $1.14 \mathrm{~cm}$ in the upper boundary $(u)$ (Figure 10). In Figures 10 and 11, some modelling results are presented. 


$$
\begin{aligned}
& u=\gamma_{\max } \times \mathrm{H} \\
& u=0.00019 \times 60 \mathrm{~m}=1.14 \mathrm{~cm}
\end{aligned}
$$

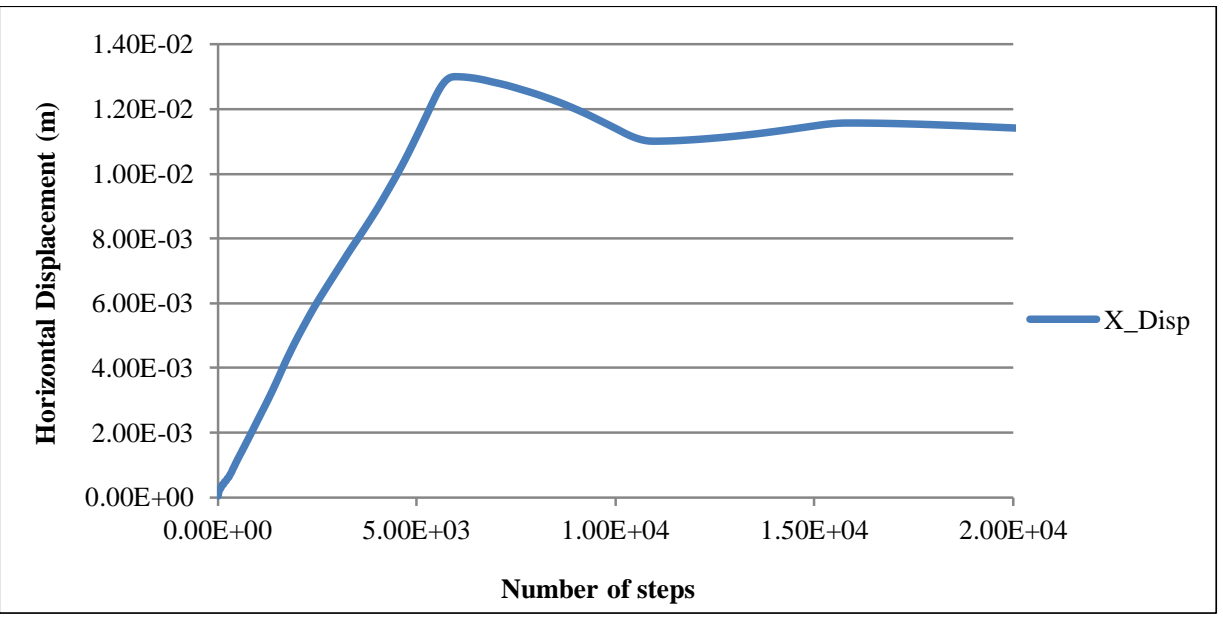

Figure 10. Horizontal displacement of the model at the upper boundary to the solving steps

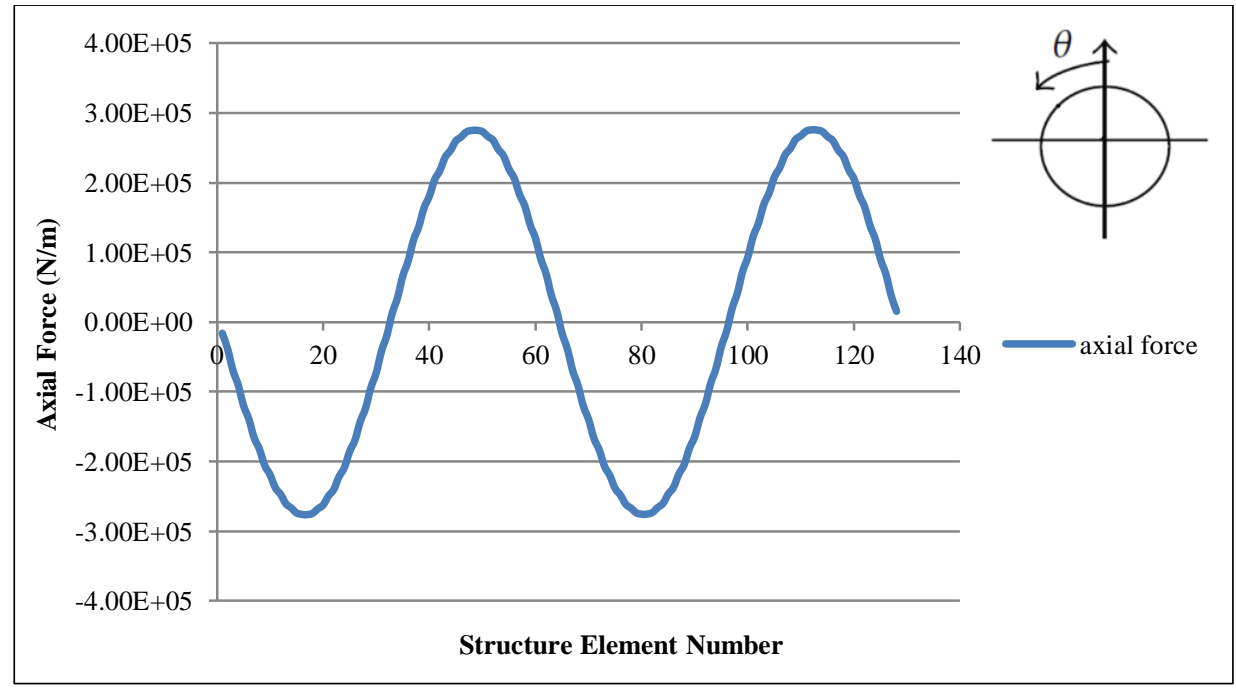

Figure 11. The axial force enters the tunnel structure around the tunnel counter-clockwise in no-slip condition

Table 6. shows the results of seismic validation with the results of analytical solutions under full-slip and no-slip conditions. Table 7. presents the difference between the analytical methods and the numerical method for estimation of structural internal forces.

Table 6. The Absolute value of maximum internal forces obtained in numerical modeling and analytical methods

\begin{tabular}{ccccccc}
\hline & Full-Slip & \multicolumn{5}{c}{ No-Slip } \\
\hline$V_{\max }$ & $M_{\max }$ & $T_{\max }$ & $V_{\max }$ & $M_{\max }$ & $T_{\max }$ & \\
$(\mathrm{KN} / \mathrm{m})$ & $(\mathrm{KNm} / \mathrm{m})$ & $(\mathrm{KN} / \mathrm{m})$ & $(\mathrm{KN} / \mathrm{m})$ & $(\mathrm{KNm} / \mathrm{m})$ & $(\mathrm{KN} / \mathrm{m})$ & \\
\multirow{2}{*}{14.48} & 12.94 & 3.15 & 7.79 & 12.69 & 275.6 & Finite Difference Code \\
& 13.712 & 3.098 & & 13.712 & 283.3783 & Wang, 1993 \\
\multirow{2}{*}{6.19} & 13.708 & 3.098 & 6.19 & 13.708 & 6.196 & Penzien, 2000 \\
& 13.718 & 3.099 & & 13.48 & 283.39 & Park at al, 2009 \\
& 13.718 & 3.100 & & 145.491 & 295.12 & Bobet, (2010) \\
\hline
\end{tabular}


Table 7. Percentage difference of maximum internal forces obtained in numerical modeling and analytical solutions

\begin{tabular}{ccccccccc}
\hline \multirow{2}{*}{$\begin{array}{c}\text { Structural internal } \\
\text { forces }\end{array}$} & $\begin{array}{c}\text { Percentage difference } \\
\text { with Wang } \%\end{array}$ & $\begin{array}{c}\text { Percentage difference } \\
\text { with Penzien } \%\end{array}$ & $\begin{array}{c}\text { Percentage difference } \\
\text { with Park\% }\end{array}$ & $\begin{array}{c}\text { Percentage difference } \\
\text { with Bobet } \%\end{array}$ \\
\cline { 2 - 8 } & No-Slip & Full-Slip & No-Slip & Full-Slip & No-Slip & Full-Slip & No-Slip & Full-Slip \\
$T_{\max }$ & 2.74 & 1.65 & 4348 & 1.65 & 2.74 & 1.61 & 6.61 & 1.58 \\
$M_{\max }$ & 7.45 & 5.63 & 7.42 & 5.60 & 5.86 & 5.67 & 1046.5 & 5.67 \\
$V_{\max }$ & - & - & 20.5 & 133.9 & - & - & - & - \\
\hline
\end{tabular}

\subsubsection{Numerical and Analytical Modelling with Different Values of Soil Stiffness and Shear Strain}

For a more comprehensive validation, the simultaneous effect of soil type and spectral content on the percentage difference between numerical and analytical modelling was studied. Meanwhile, a shear wave velocity of the earthquake was chosen to cover a variety of soils from loose soil to hard soil and the ratio of flexibility $(F)$ being less than 1 to very large values. Such an analysis allows studying the effect of free-field shear strain $\left(\gamma_{\max }\right)$ depth at the tunnel. In Table 8, the values of the parameters are presented according to different scenarios of the earthquake.

Table 8. Results obtained from all scenarios

\begin{tabular}{ccccccccccc}
\hline Parameter & \multicolumn{10}{c}{ Parameter value } \\
\hline$C_{s}(\mathrm{~m} / \mathrm{s})$ & 30 & 61 & 100 & 150 & 200 & 300 & 350 & 490 \\
$E_{m}(\mathrm{MPa})$ & 2.47 & 10.62 & 29.6 & 82.8 & 150.9 & 355.2 & 516.5 & 1126.2 & 5052.7 \\
$\gamma_{\max }$ & 0.0026 & 0.0023 & 0.0020 & 0.001 & 0.00084 & 0.00069 & 0.0005 & 0.00019 & 0.000034 \\
$G / G_{\max }$ & 0.53 & 0.55 & 0.58 & 0.71 & 0.73 & 0.77 & 0.82 & 0.91 \\
$F$ & 0.23 & 1 & 2.793 & 7.814 & 14.241 & 33.523 & 48.747 & 106.29 & 476.87 \\
$u(\mathrm{~cm})$ & 15.6 & 13.8 & 12 & 6 & 5.04 & 4.14 & 3 & 0.98 \\
\hline
\end{tabular}

As shown in Figures 12 and 13, under full-slip conditions, the results of finite difference method (FDM) are well suited to the analytical solution for estimation of axial force and bending moment in range $0.23 \leq F \leq 476.78$. According to this diagram, the range $0.23 \leq F \leq 2.79$ first increases the axial force and bending moment, and then both the axial force and the moment decrease from $F=2.79$. As can be seen in Figures 14 and 15, it is concluded that under no-slip conditions, estimating the axial force and the bending moment to the closed-form solutions of Park and Wang's solutions in the range $0.23 \leq F \leq 476.78$ are highly consistent with the numerical analysis of quasi-static method. Moreover, according to this diagram, the results of the Penzien's solution for estimating axial force in $F<1$ are approximately the same with numerical methods and other analytical solutions. It can be concluded that the weakness of the Penzien's solution can be resolved in the estimation of the axial force in the $\mathrm{F}<1$, while in proportions larger than 1, the Penzien's solution also has a great deal of difference with numerical methods and other solutions and considered the axial force less other methods. The Bobet's solution in the range $0.23 \leq F \leq 48.74$ is in good agreement with the numerical method for estimation of axial force, but by increasing the $\mathrm{F}>48.74$, this solution yields a greater axial force (Figure 14). According to Figure 15, the Bobet's solution in the range $0.23 \leq F \leq 2.79$ has a good agreement with the numerical method and other solutions for estimation of the bending moments. In comparison, in the $\mathrm{F}>2.79$, the bending momentum is achieved greater than other methods and this method shows a very large difference for $F=476.78$, suggesting the inefficiency and overcoming this solution for estimating the bending moment in the mentioned interval. Three other analytical methods yield estimations rather similar to those of numerical modeling for the bending moment in all ranges of the $\mathrm{F}$. 


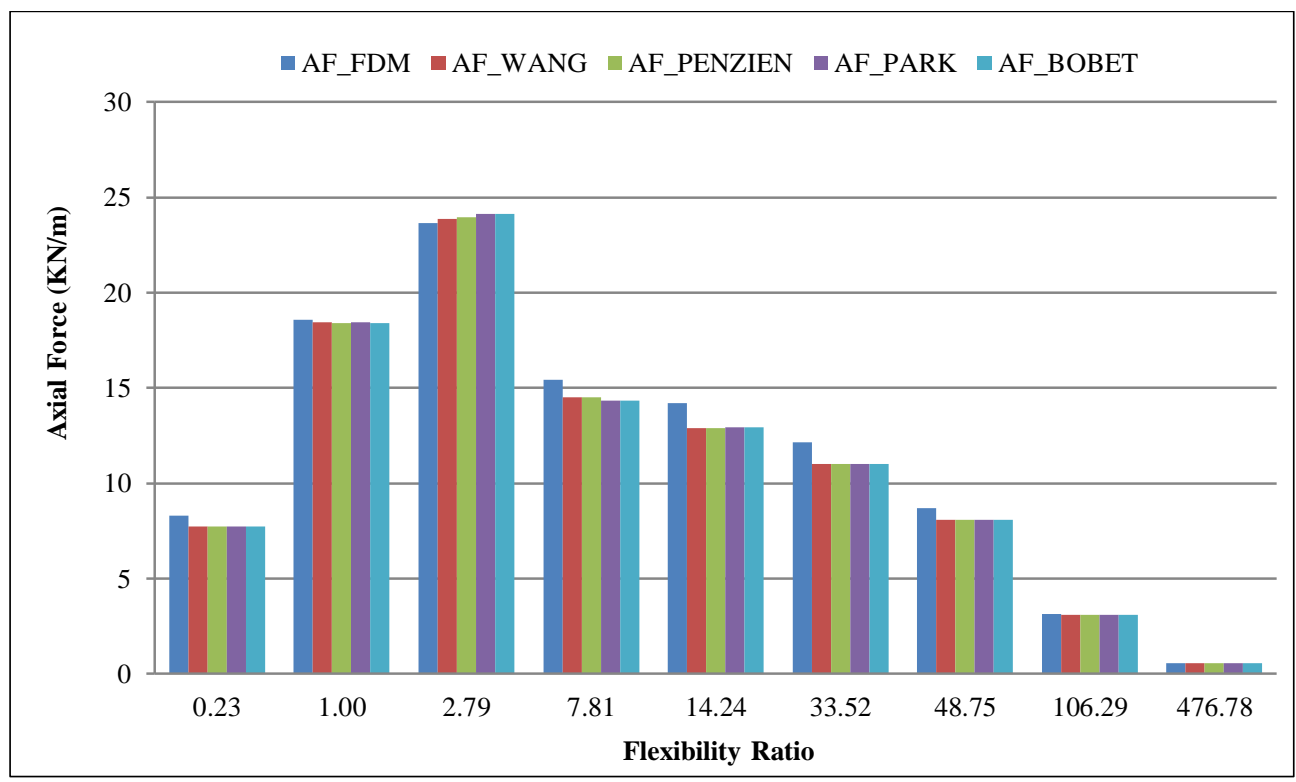

Figure 12. Maximum axial force output versus flexibility ratio in full-slip condition

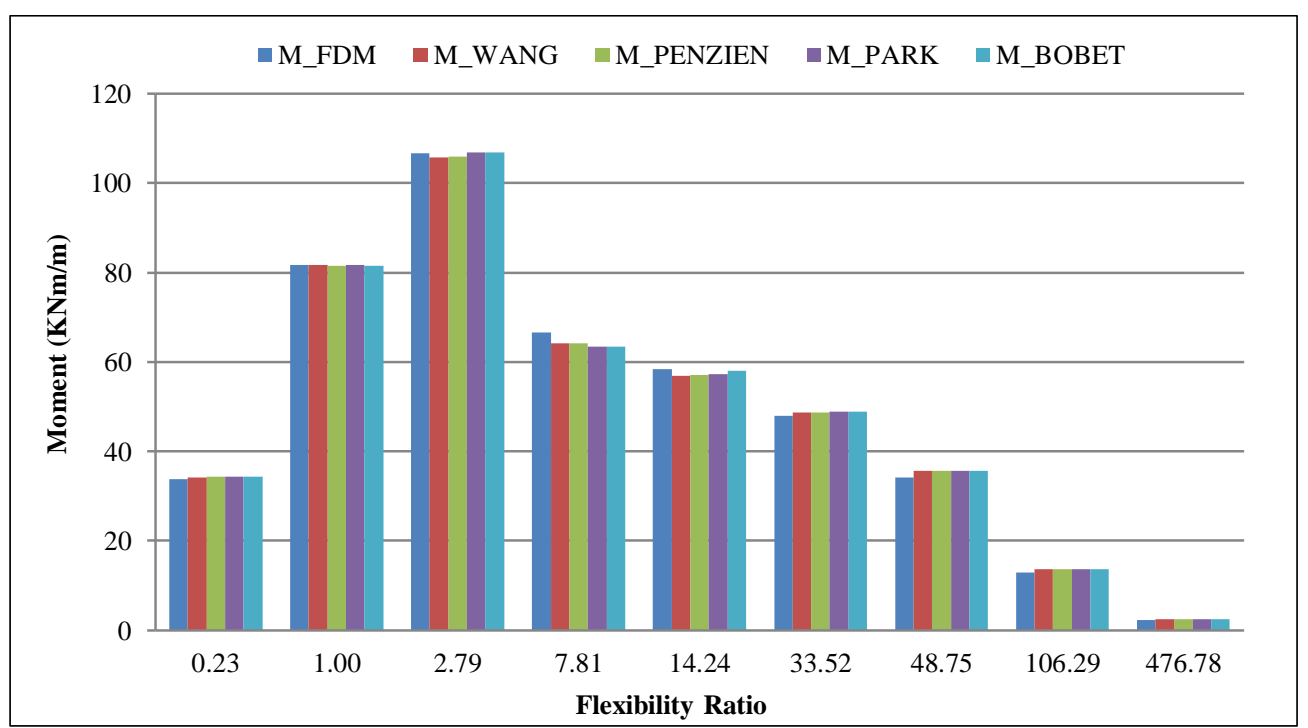

Figure 13. Maximum moment output versus flexibility ratio in full-slip condition

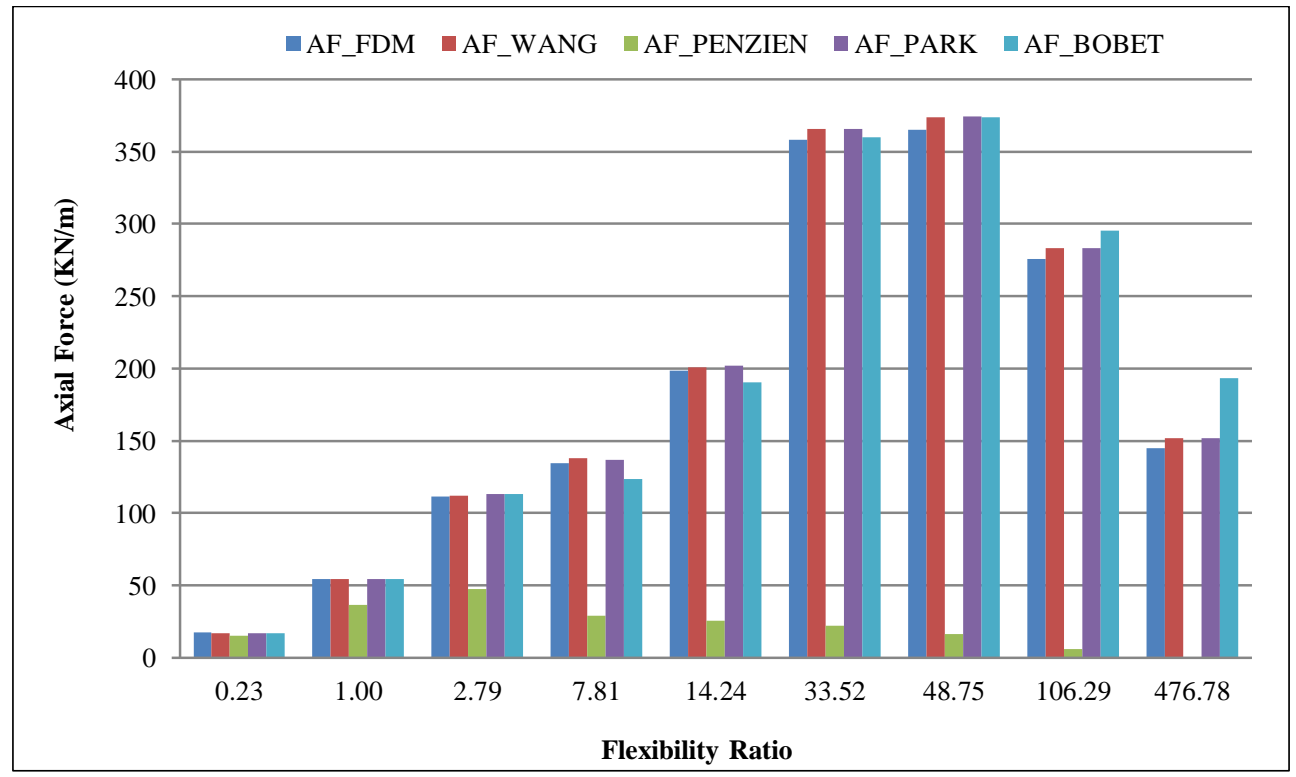

Figure 14. Maximum axial force output versus flexibility ratio in no-slip condition 


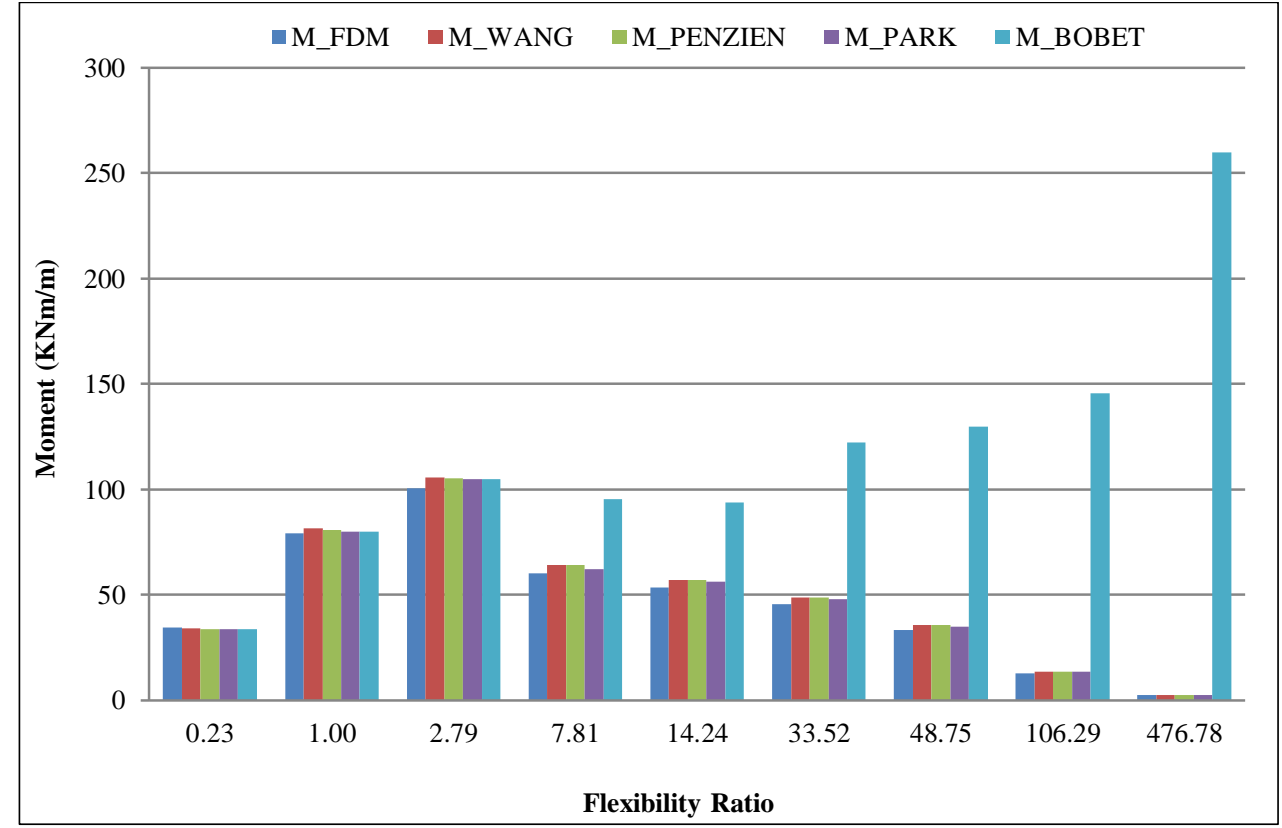

Figure 15. Maximum moment output versus flexibility ratio in no-slip condition

\subsubsection{Numerical Modelling Under Realistic Conditions of Interaction}

In recent years, almost all quasi-static numerical analyses have examined assumptions same as those of analytical solutions. These methods, however, have limitations including full-slip and no-slip conditions between the lining and soil. In the meantime, References [7-11], used analytical methods to validate these assumptions. In this section, using valid relationships, the actual interaction conditions between the tunnel lining and soil are evaluated in the quasi-static analysis and compared with analytical solutions. In the context of the slip between the lining and the soil for the actual interaction conditions, Molins \& Arnau (2011 a) carried out studies based on full-scale experiments on the segments lining at line 9 of the Barcelon subway. They concluded that taking full consideration of the tangent rigidity $\left(\mathrm{K}_{\mathrm{t}}=\mathrm{K}_{\mathrm{r}} / 3\right)$ between the lining and the soil yields most appropriate results with the experimental findings to determine the maximum stresses on the tunnel crown and stress transfer. Reducing the amount of tangential rigidity decrease in peak axial stress and stress distribution and generates significant stresses on the invert of the tunnel lining. Ignoring the tangential rigidity does not provide uniform distribution of axial stress. Therefore, paying enough attention to tangential mechanisms is very important in determining the structural behavior of segmental tunnel lining in difficult ground conditions [24].

Considering that the actual interaction conditions between the tunnel lining and the soil are between full-slip and no-slip conditions [3-7-11], the interface element with the obtained radial rigidity coefficient from Eq. (37) in Winkler's theory and other parameters according to Table 9. were used. The accuracy of the Winkler's analytic relationship has been proven based on the full-scale Molins \& Arnau (2011a) segmental lining tests. According to Molins \& Arnau (2011a) experiments, the tangential stiffness coefficient should at best be considered as a third of their radial stiffness coefficient according to equations (38) [24]. The actual value of the friction angle of the interface element between the concrete (lining) and sand or sand mixed with clay or silt (soil type in the borehole BH-SL612) was considered to be $17^{\circ}$ according to the reference [25]. According to this reference, the real cohesion between them was estimated to be $20 \mathrm{kN}$.

$K_{r}=\frac{E_{S}}{R\left(1+v_{S}\right)}$

$K_{t}=\frac{K_{r}}{3}$

Where $E_{S}$ is Young's modulus the soil around the tunnel and $R$ is the radius of the tunnel.

Table 9. The values of the interface element parameters between the tunnel lining and soil in Real interaction condition

\begin{tabular}{cc}
\hline Parameter value & Parameter \\
\hline Normal stiffness coefficient between lining and soil $(\mathrm{Pa} / \mathrm{m})$ & $1.72 \times 10^{8}$ \\
Shear stiffness coefficient between lining and soil $(\mathrm{Pa} / \mathrm{m})$ & $5.73 \times 10^{7}$ \\
Cohesion between lining and soil $(\mathrm{Pa})$ & $20 \times 10^{3}$ \\
Angle of dilation between lining and soil & 0.0 \\
\hline
\end{tabular}




\begin{tabular}{cc}
\hline Angle of friction between the lining and soil & 17 \\
Tensile bond strength between the lining and soil (Pa) & $6.7 \times 10^{4}$ \\
Shear strength ratio to tensile strength between lining and soil & 100 \\
Slip conditions between the lining and soil & on \\
\hline
\end{tabular}

In Figures. 16 and 17, some results of numerical modelling for a seismic loading are presented for a quasi-static modeling under realistic interaction conditions. As can be seen, the maximum axial force is at $47 / 36 \mathrm{kN}$, which is lower than at the no-slip condition $(275.6 \mathrm{kN})$ and also is greater than the axial force at full-slip $(3.15 \mathrm{kN})$. The maximum bending moment reached $13.29 \mathrm{kN}$.m which has small difference compared with no-slip and full-slip conditions with values of 12.69 and $12.94 \mathrm{KN}$.m. As can be seen from the results, under no-slip conditions, full-slip and real interaction, the bending moment, in comparison with the axial force, changes very slightly in relation to the change in the interaction between the lining and the soil. This bending moment is affected most importantly by the geometry and modified shape of the tunnel lining; which, in turn, is affected by the free-field shear strain. As shown in Figure 17, the distribution of the bending moment around the tunnel lining is symmetric. In Table 10, the difference between the maximum obtained internal forces in numerical modeling under realistic conditions of interaction and analytical solutions under conditions of no-slip and complete slip is presented. The results of this section are in accordance with the findings of Sederat et al. (2009).

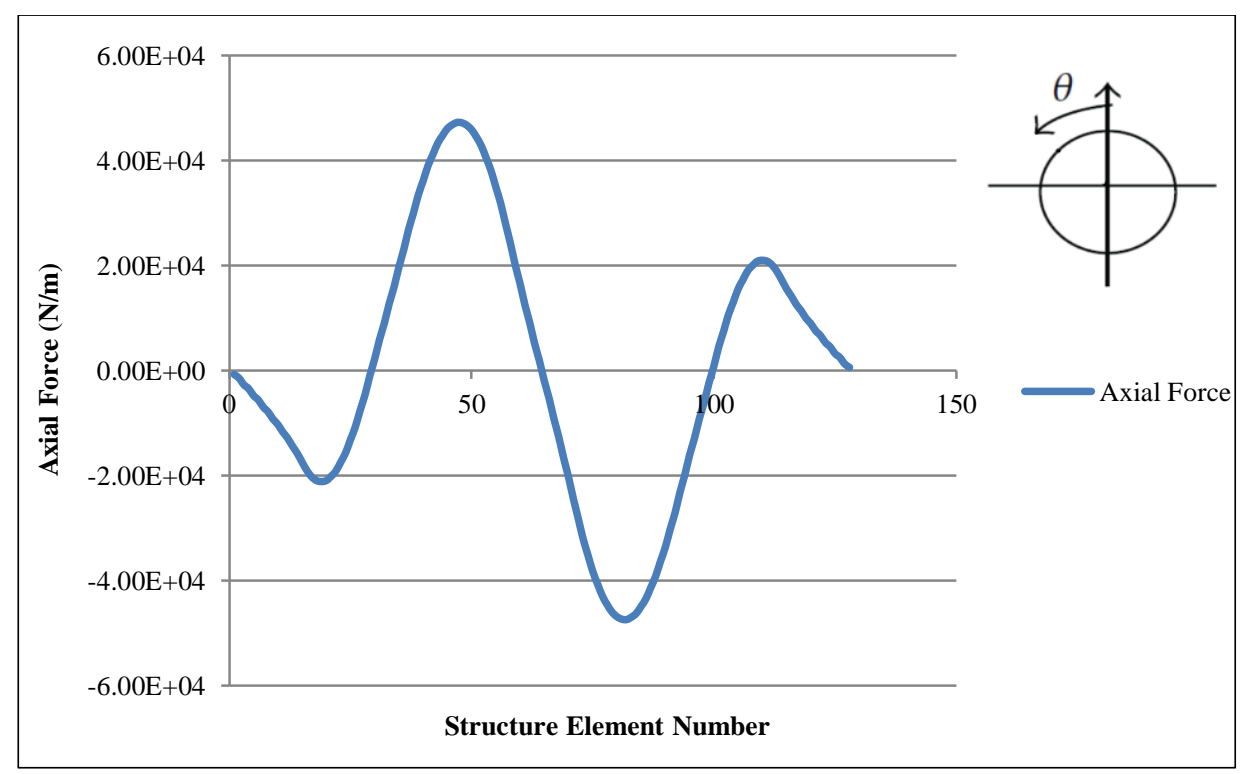

Figure 16. The axial force enters the tunnel structure around the tunnel counter-clockwise in real interaction condition

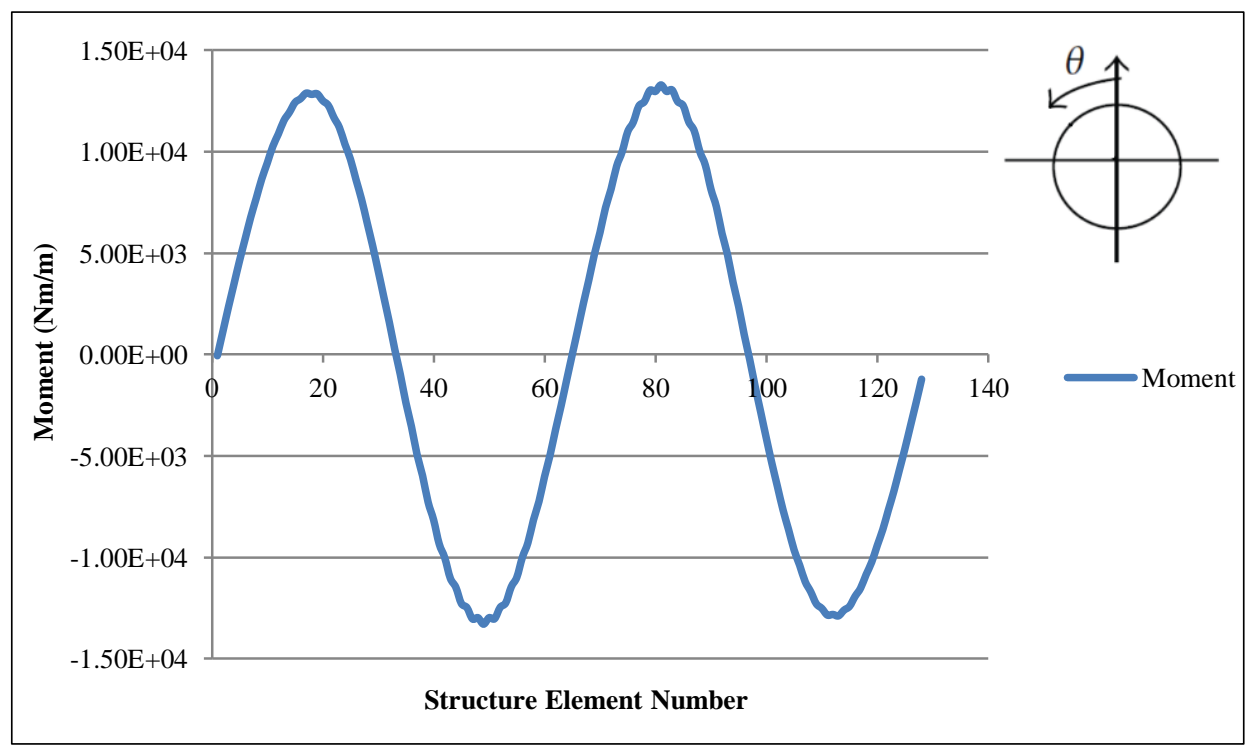

Figure 17. The moment enters the tunnel structure around the tunnel counter-clockwise in real interaction condition 
Table 10. Percentage difference of the maximum internal forces obtained in numerical modeling under real interaction condition and analytical solutions

\begin{tabular}{ccccccccc}
\hline $\begin{array}{c}\text { Structural } \\
\text { internal forces }\end{array}$ & $\begin{array}{c}\text { Percentage difference } \\
\text { with Wang \% }\end{array}$ & \multicolumn{2}{c}{$\begin{array}{c}\text { Percentage difference } \\
\text { with Penzien } \%\end{array}$} & $\begin{array}{c}\text { Percentage difference } \\
\text { with Park\% }\end{array}$ & \multicolumn{2}{c}{$\begin{array}{c}\text { Percentage difference with } \\
\text { Bobet \% }\end{array}$} \\
\cline { 2 - 9 } & No-Slip & Full-Slip & No-Slip & Full-Slip & No-Slip & Full-Slip & No-Slip & Full-Slip \\
$T_{\max }$ & 498.34 & 1428.7 & 664.36 & 1428.7 & 498.37 & 1428.2 & 523.14 & 1427.7 \\
$M_{\max }$ & 3 & 3 & 3 & 3 & 1.4 & 3.1 & 994.74 & 3.1 \\
$V_{\max }$ & - & - & 2.9 & 2.9 & - & - & - & - \\
\hline
\end{tabular}

Among the available analytical solutions, only the solution presented by Park et al. (2009) can be considered for analysing the effect of the slip between the lining and the soil. In the equations written in "section 3.1.2.3", the coefficient of shear flexibility values $D=0$ and $D \rightarrow \infty$ are used for no-slip full-slip conditions, respectively. For this purpose, the values of the coefficient of shear flexibility $D=0.175 \times 10^{-7}$ obtained from equation (39) were incorporated in relations (40) to (42) to simulate the actual interaction conditions and the validation of the Park's solution under the conditions of real interaction. As presented in Table 11, the Park's analytical solution has the ability to simulate the actual interaction of the lining and soil; besides, the percentage of tolerance between these two methods is very low and acceptable. This observation can be explained by the high number of slip parameters of the numerical method in simulating the interface element; while Park's analytical method employs only one parameter called shear flexibility coefficient for slip behaviour.

$$
\begin{aligned}
& D=\frac{1}{K_{S}}=\frac{1}{5.73 \times 10^{7}}=0.175 \times 10^{-7} \\
& T_{P T T O}=-\frac{\left(1-v_{S}\right) \mathrm{E}_{S} \gamma_{C} R}{\left(1+v_{S}\right) \Delta^{\prime \prime}}\left\{2 F+\left(1-2 v_{S}\right) \mathrm{C}+4+D \frac{4 E_{S}}{R\left(1+v_{S}\right)}\right\} \cos 2\left(\theta+\frac{\pi}{4}\right) \\
& M_{\text {PTTO }}=-\frac{\left(1-v_{S}\right) \mathrm{E}_{S} \gamma_{c} R^{2}}{\left(1+v_{S}\right) \Delta}\left\{\left(1-2 v_{s}\right) \mathrm{C}+2+D \frac{4 E_{S}}{R\left(1+v_{s}\right)}\right\} \cos 2\left(\theta+\frac{\pi}{4}\right) \\
& \Delta^{\prime \prime}=C F\left(1-2 v_{s}\right)+F\left(3-2 v_{s}\right)+\mathrm{C}\left[2.5-8 v_{s}+6 v_{s}^{2}\right]+6-8 v_{s}+2 D \frac{\left(2 \mathrm{~F}+5-6 v_{s}\right) \mathrm{E}_{s}}{R\left(1+v_{s}\right)}
\end{aligned}
$$

Where $\Delta^{\prime \prime}$ is the coefficient of the lining response under different sliding conditions in the Park's method.

Table 11. The Absolute value of maximum internal forces and percent difference in numerical modeling and park analytical solution under real interaction condition

\begin{tabular}{cccc}
\hline \multicolumn{5}{c}{ Real interaction } \\
\hline $\mathbf{V}_{\text {Max }}(\mathbf{K N} / \mathbf{m})$ & $\mathbf{M}_{\text {Max }}(\mathbf{K N m} / \mathbf{m})$ & $\mathbf{T}_{\text {Max }}(\mathbf{K N} / \mathbf{m})$ & \\
\hline 6.37 & 13.29 & 47.36 & Finite Difference Code \\
- & 13.67 & 49.23 & Park et al, 2009 \\
& 2.8 & 3.8 & Difference Percentage (\%) \\
\hline
\end{tabular}

\section{Conclusion}

Poorly defined conditions of some analytical solutions including the Penzien (2000) and Bobet's (2010) solutions taken to formulate interaction between the lining and the soil under no-slip conditions lead to some results contradictive with those of other analytical methods and numerical methods.

The results of the present research can be divided into three main parts. The first part relates to the comparison of the results of quasi-static numerical analysis of an urban environment with analytical solutions. The results of this section showed the weakness of the Penzien and Bobet's solution in the estimation of axial force and moment in noslip condition, respectively. In the second part, a series of validations under different shear wave velocities were performed to investigate the poor performance of the Penzien's analytical solution and to determine the universality of the Wang and Park's analytical solution. The results showed that under no-slip conditions, Penzien's analytical solution for estimating axial force provides similar results in numerical methods only for $\mathrm{F} \leq 1$. Also, the Bobet's solution for estimating the bending moment under no-slip conditions for the $\mathrm{F} \leq 2.79$ yields results similar to numerical methods and other analytical solutions. The Wang and Park's analytical solution in all earthquake scenarios and different flexibility ratios have very accurate results with quasi-static numerical analysis. In the last section, to show the effect of the slip between the tunnel lining and soil in estimating the internal forces during the earthquake loading, as well as the reliability coefficient of flexibility the Park's solution in terms of slipping conditions, a quasistatic numerical analysis was constructed under real slip conditions between the lining and the soil. The results showed 
a significant decrease in the axial force and bending moment. Moreover, the numerical analysis results were in good agreement with the analytical solution results of the Park.

Considering the presented quantitative results, a general conclusion can be drawn. Penzien's solutions should not be used in no-slip tunnel design under seismic loading and Wang's analytical solutions should be used with caution as an initial estimate. However, the analytical solution of Park et al, because of the ability to simulate the slip in the interface of the lining-soil and the matching of its results by numerical methods in different types of soil (a wide range of $F$ ), provides more accurate estimates in seismic loading than other methods. As a result, the Park's solution has applicability in a variety of earthquake, soil, and slip conditions between the lining and the soil.

\section{References}

[1] Do, Ngoc Anh. "Numerical analyses of segmental tunnel lining under static and dynamic loads." PhD diss., Lyon, INSA, 2014.

[2] Wang, J. N. "Seismic Design of Tunnels: A State-of-the-Art Approach. Monograph 7. New York: Parsons Brinckerhoff Quade and Douglas." (1993).

[3] Hashash, Youssef M.A., Jeffrey J. Hook, Birger Schmidt, and John I-Chiang Yao. "Seismic Design and Analysis of Underground Structures." Tunnelling and Underground Space Technology 16, no. 4 (October 2001): 247-293. doi:10.1016/s08867798(01)00051-7.

[4] Bobet, A. "Effect of Pore Water Pressure on Tunnel Support During Static and Seismic Loading." Tunnelling and Underground Space Technology 18, no. 4 (August 2003): 377-393. doi:10.1016/s0886-7798(03)00008-7.

[5] Hashash, Youssef M.A., Duhee Park, and John I.-Chiang Yao. "Ovaling Deformations of Circular Tunnels Under Seismic Loading, an Update on Seismic Design and Analysis of Underground Structures.” Tunnelling and Underground Space Technology 20, no. 5 (September 2005): 435-441. doi:10.1016/j.tust.2005.02.004.

[6Pakbaz, Mohammad C., and Akbar Yareevand. "2-D Analysis of Circular Tunnel Against Earthquake Loading.” Tunnelling and Underground Space Technology 20, no. 5 (September 2005): 411-417. doi:10.1016/j.tust.2005.01.006.

[7] Sedarat, Hassan, Alexander Kozak, Youssef M.A. Hashash, Anoosh Shamsabadi, and Alex Krimotat. "Contact Interface in Seismic Analysis of Circular Tunnels." Tunnelling and Underground Space Technology 24, no. 4 (July 2009): $482-490$. doi:10.1016/j.tust.2008.11.002.

[8] Park, Kyung-Ho, Kullachai Tantayopin, Bituporn Tontavanich, and Adisorn Owatsiriwong. "Analytical Solution for SeismicInduced Ovaling of Circular Tunnel Lining Under No-Slip Interface Conditions: A Revisit." Tunnelling and Underground Space Technology 24, no. 2 (March 2009): 231-235. doi:10.1016/j.tust.2008.07.001.

[9] Bobet, Antonio. "Drained and Undrained Response of Deep Tunnels Subjected to Far-Field Shear Loading." Tunnelling and Underground Space Technology 25, no. 1 (January 2010): 21-31. doi:10.1016/j.tust.2009.08.001.

[10] Kouretzis, George P., Scott W. Sloan, and John P. Carter. "Effect of Interface Friction on Tunnel Liner Internal Forces Due to Seismic S- and P-Wave Propagation.” Soil Dynamics and Earthquake Engineering 46 (March 2013): 41-51. doi:10.1016/j.soildyn.2012.12.010.

[11] Kontoe, S., V. Avgerinos, and D.M. Potts. "Numerical Validation of Analytical Solutions and Their Use for Equivalent-Linear Seismic Analysis of Circular Tunnels." Soil Dynamics and Earthquake Engineering 66 (November 2014): 206-219. doi:10.1016/j.soildyn.2014.07.004.

[12] Akhlaghi, Tohid, and Ali Nikkar. "Effect of Vertically Propagating Shear Waves on Seismic Behavior of Circular Tunnels." The Scientific World Journal 2014 (2014): 1-10. doi:10.1155/2014/806092.

[13] Do, Ngoc-Anh, Daniel Dias, Pierpaolo Oreste, and Irini Djeran-Maigre. "2D Numerical Investigation of Segmental Tunnel Lining Under Seismic Loading." Soil Dynamics and Earthquake Engineering 72 (May 2015): 66-76. doi:10.1016/j.soildyn.2015.01.015.

[14] Ahab Construction Company. Engineering geology report of metro tehran line 6. Tehran Urben Railway Corporation. (2008).

[15] Darya Khak Pey Consulting Engineers. Geotechnic studies report southern part of metro tehran line 6. Tehran Urben Railway Corporation. (2009).

[16] GmbH Consulting Engineers. Report on the static design of the segmental lining for MetroTehran Line 6. Tehran Urben Railway Corporation. (2011)

[17] Ohsaki, Y., \& Iwasaki, R. On Dynamic Shear Moduli And Poisson's Ratios Of Soil Deposits. Soil and Foundations 13 (1973): 61-73. doi: 10.3208/sandf1972.13.4_61.

[18] Das B M. Principles of soil dynamics. [M]. Boston: PWS-Kent Publish-ing Co., 570. (1993).

[19] Bazaz JB and Besharat V. An investigation on seismic analysis of shallow tunnels in soil medium. In: Proceedings of the 14th 
world conference on earthquake engineering. Beijing (China); October 12-17. (2008).

[20] Park KH, Tantayopin K and Tontavanich B. Analytical solutions for seismic design of tunnel lining in Bangkok MRT Subway. In: Proceedings of the international symposium on underground excavation and tunnelling. Bangkok (Thailand); $2-4$ February. (2006).

[21] Peck, R. B., Hendron, A. J., \& Mohraz, B. State of the art of soft ground tunneling. In: Proceedings of 1st Rapid Excavation and Tunneling Conference, AIME Chicago; vol1: 259 - 285. (1972).

[22] Federal Highway Administration (FHWA), "Technical manual for design and construction of road tunnels - Civil elements", Tech. rep., Report N FHWA-NHI-10-034. (2009).

[23] Zurlo MA. Seismic response of circular tunnels: numerical validation of closed form solutions. In: Proceedings of the 1st civil and environmental engineering student conference. Imperial College London; 25-26 June 2012.

[24] Molins, Climent, and Oriol Arnau. "Experimental and Analytical Study of the Structural Response of Segmental Tunnel Linings Based on an in Situ Loading Test." Tunnelling and Underground Space Technology 26, no. 6 (November 2011): 764-777. doi:10.1016/j.tust.2011.05.002.

[25] Naval Facilities Engineering Command Publications Transmittal: Foundations And Earth Structures, September 1986. SN 0525-LP-300-7071. 